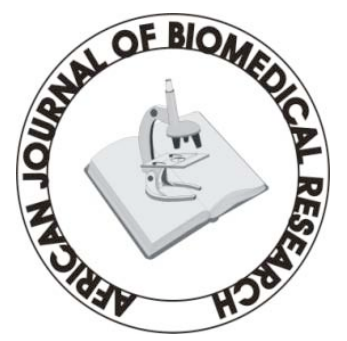

Full-text available at http://www.ajbrui.com http://www.bioline.br/md http://www.ajol.com

Received:

February 2008

Accepted (Revised): August 2008

Published

September 2008
Full Length Research Article

\section{Evidence of Environmental Pollution in Caprine Brains obtained from a Relatively Unindustrialized Area in Nigeria.}

\author{
Igado, O.O*. Olopade, J.O., Onwuka, S.K., Chukwudi, A.C., \\ Daramola, O.A., Ajufo, U.E. \\ Department of Veterinary Anatomy, \\ University of Ibadan, Nigeria.
}

\section{ABSTRACT}

The concentration of metals (Iron-Fe, Zinc-Zn, Copper-Cu, Aluminum-Al, Molybdenum-Mo, Vanadium- $\mathrm{Va}$, and Lead-Pb) in the different regions of the brain of goats in a relatively unindustrialized area in Nigeria was investigated using the Atomic Absorption Spectrophotometer. The highest mean concentration of $98.66 \mathrm{ppm}$ was for Fe in the olfactory bulb while the least of $0.07 \mathrm{ppm}$ was for Mo in the thalamus. The levels of $\mathrm{Zn}$ and Fe showed the highest significant differences across the different regions of the brain examined. All the metals analysed showed relatively high concentrations in the olfactory bulb suggesting ongoing environmental pollution. The findings suggest that this type of investigation in the brain of goats or other animals can assist in knowing the level of human exposure to environmental pollutants (especially metals) in non-industrialized areas. They can also be compared with similar data obtained from animals in known polluted environments in extrapolating the level of pollution in such areas.

(Afr. J. Biomed. Res. 11: 305 - 309)

Key Words: Metals, Brain, Olfactory bulb.

*Address for Correspondence: mayowaigado@yahoo.com 


\section{INTRODUCTION}

There has been a steady increase in the human population of most third world countries. The increase in these countries has been characterized by destructive human activities such as increased exploitation of minerals leading to pollution of the environment (Olopade et al, 2005a).

Air pollution resulting from the combustion of fossil fuels includes emissions from motor vehicle engines, power plants, fire-places and barbecues. Waste incinerators, smelters and other industrial activities may be responsible for emissions of a variety of acidic, organic and metallic compounds that may have significant health effects. Mixtures of these individual pollutants may also occur (Bascom, 1996).

Nigeria with a population of over 35 million goats has one of the largest caprine species in Africa (FAO, 1995). Due to the ubiquitous and hardy nature of this species (Gall, 1996), and their ability to go deeper into the ecosystem for their survival, it had been postulated that the species could be a better model to study the role of the environment in metal toxicity of the brain (Olopade et al, 2005b) since it has been established that the uptake of metals into the brain occur via olfactory pathways (Persson et al, 2003). A recent study using the dog in Mexico suggested a strong link between environmental pollution and incidence of neuropathologies of the brain (Calderon-Garciduenas et al, 2002).

The essence of this work is to assess the level of seven metals in five different brain regions of caprine species living Oranyan in the city of Ibadan, a relatively non-industrialized area of Nigeria.

\section{MATERIALS AND METHODS}

A total of 15 native West African Dwarf goats (8 males, 7 females) of ages less than two years were obtained from Oranyan, a non-industrialized area of Ibadan, South-West, Nigeria. The heads of the goats were processed according to the method of Olopade et al., (2005a) to remove the brains. Tissue samples of brain were separately removed from five different regions namely the olfactory bulb, the frontal cortex, thalamus, hippocampus and cerebellum. The brain samples were put in petri-dishes and allowed to macerate in the oven at $45^{\circ} \mathrm{C}$ for 3 days. The samples were analyzed for the concentrations (ppm) of seven metals which were Zinc $(\mathrm{Zn})$, Iron $(\mathrm{Fe})$, Copper $(\mathrm{Cu})$, Molybdenum (Mo), Vanadium (Va), Lead $(\mathrm{Pb})$ and Aluminum (Al) using the Atomic Absorption Spectrophotometer (AAS) according to the method described by Benas, 1968.

The data obtained were presented as mean \pm standard deviation (S.D) ppm and as bar charts and analyzed using SPSS10 package for analysis of variance

\section{RESULTS}

Most of the metals examined in this study were relatively concentrated in the olfactory bulb compared to other regions of the brain although the mean concentration ( $\mathrm{ppm}$ ) of the metals in the whole brain (all regions) was in the descending order of $\mathrm{Fe} \quad(89.54)>\mathrm{Zn}(66.41)>\mathrm{Cu} \quad(2.77)>\mathrm{Va}$ (0.34)> Pb (0.21)>Al (0.09)>Mo (0.78). Analysis of variance showed a significant difference across most of the brain regions in the mean concentrations of $\mathrm{Zn}$ and $\mathrm{Fe}$.

Table 1: Concentrations (ppm) of some metals in different regions of the brain of WAD goat (male + female) in Nigeria (mean + standard deviation)

\begin{tabular}{l|lllllll}
\hline Factor & $\mathrm{Va}$ & $\mathrm{Pb}$ & $\mathrm{Cu}$ & $\mathrm{Fe}$ & $\mathrm{Mo}$ & $\mathrm{Zn}$ & $\boldsymbol{A l}$ \\
\hline $\mathrm{A}$ & $0.39 \pm 0.07$ & $0.22 \pm 0.06$ & $2.89 \pm 0.73$ & $98.66 \pm 23.02 *$ & $0.09 \pm 0.04$ & $79.59 \pm 9.1 *$ & $0.10 \pm 0.04$ \\
$\mathrm{~B}$ & $0.32 \pm 0.14$ & $0.21 \pm 0.05$ & $2.9 \pm 0.68$ & $97.03 \pm 7.44 *$ & $0.08 \pm 0.03$ & 41.6612 .69 & $0.09 \pm 0.04$ \\
$\mathrm{C}$ & $0.35 \pm 0.11$ & $0.19 \pm 0.06$ & $2.8 \pm 0.65$ & $84.19 \pm 22.15$ & $0.07 \pm 0.05$ & $60.27 \pm 15.88$ & $0.08 \pm 0.02$ \\
$\mathrm{D}$ & $0.34 \pm 0.06$ & $0.19 \pm 0.04$ & $2.6 \pm 0.59$ & $83.27 \pm 14.58$ & $0.07 \pm 0.03$ & $64.92 \pm 18.98$ & $0.09 \pm 0.03$ \\
$\mathrm{E}$ & $0.29 \pm 0.08$ & $0.223 \pm 0.052$ & $2.7 \pm 0.65$ & $84.56 \pm 18.23$ & $0.08 \pm 0.05$ & $85.59 \pm 13.10 *$ & $0.10 \pm 0.04$ \\
\hline Total & $0.34 \pm 0.10$ & $0.21 \pm 0.05$ & $2.77 \pm 0.64$ & $89.54 \pm 18.81$ & $0.08 \pm 0.04$ & $66.41 \pm 20.89$ & $0.09 \pm 0.04$ \\
\hline
\end{tabular}

*Significant difference; Keys: A = Olfactory bulb, B = Cerebral cortex. C = Thalamus, D = Hippocampus, E = Cerebellum. 
Table 2:

Concentrations $(\mathrm{ppm})$ of some metals in different regions of the brain of male WAD goat in Nigeria (mean \pm standard deviation)

\begin{tabular}{l|lllllll}
\hline Factor & $\mathrm{Va}$ & $\mathrm{Pb}$ & $\mathrm{Cu}$ & $\mathrm{Fe}$ & $\mathrm{Mo}$ & $\mathrm{Zn}$ & $\mathrm{Al}$ \\
\hline $\mathrm{A}$ & $0.37 \pm 0.08$ & $0.21 \pm 0.06$ & $2.95 \pm 0.60$ & $99.51 \pm 26.20$ & $0.08 \pm 0.3$ & $78.74 \pm 11.74$ & $0.09 \pm 0.03$ \\
$\mathrm{~B}$ & $0.35 \pm 0.09$ & $0.20 \pm 0.04$ & $2.68 \pm 0.31$ & $98.16 \pm 7.14$ & $0.07 \pm 0.04$ & $31.25 \pm 14.72$ & $0.08 \pm 0.03$ \\
$\mathrm{C}$ & $0.36 \pm 0.16$ & $0.18 \pm 0.06$ & $2.77 \pm 0.74$ & $88.14 \pm 22.24$ & $0.09 \pm 0.06$ & $54.17 \pm 18.07$ & $0.09 \pm 0.02$ \\
$\mathrm{D}$ & $0.34 \pm 0.07$ & $0.19 \pm 0.04$ & $2.47 \pm 0.53$ & $86.15 \pm 13.59$ & $0.07 \pm 0.03$ & $52.53 \pm 12.64$ & $0.09 \pm 0.04$ \\
& & & & & & & \\
$\mathrm{E}$ & $0.28 \pm 0.09$ & $0.24 \pm 0.06$ & $2.58 \pm 0.46$ & $83.71 \pm 12.13$ & $0.08 \pm 0.03$ & $76.88 \pm 28.25$ & $0.09 \pm 0.04$ \\
& & & & & & & \\
\hline Total & $0.34 \pm 0.10$ & $0.20 \pm 0.05$ & $2.69 \pm 0.54$ & $91.13 \pm 17.98$ & $0.08 \pm 0.04$ & $58.71 \pm 24.72$ & $0.09 \pm 0.03$ \\
\hline
\end{tabular}

Keys: $\mathrm{A}=$ Olfactory bulb, $\mathrm{B}=$ Cerebral cortex. $\mathrm{C}=$ Thalamus, $\mathrm{D}=$ Hippocampus, $\mathrm{E}=$ Cerebellum.

Table 3: Concentrations (ppm) of some metals in different regions of the brain of female WAD goat in Nigeria (mean +standard deviation)

\begin{tabular}{l|lllllll}
\hline Factor & $\mathrm{Va}$ & $\mathrm{Pb}$ & $\mathrm{Cu}$ & $\mathrm{Fe}$ & $\mathrm{Mo}$ & $\mathrm{Zn}$ & $A \boldsymbol{l}$ \\
\hline $\mathrm{A}$ & $0.41 \pm 0.07$ & $0.23 \pm 0.05$ & $2.81 \pm 0.990$ & $98.55 \pm 20.11$ & $0.10 \pm 0.04$ & $80.57 \pm 5.49$ & $0.12 \pm 0.04$ \\
$\mathrm{~B}$ & $0.29 \pm 0.18$ & $0.23 \pm 0.07$ & $2.99 \pm 0.91$ & $95.75 \pm 8.13$ & $0.08 \pm 0.02$ & $49.65 \pm 11.45^{*}$ & $0.10 \pm 0.04$ \\
$\mathrm{C}$ & $0.330 \pm .06$ & $0.21 \pm 0.06$ & $2.90 \pm 0.58$ & $79.67 \pm 22.86$ & $0.14 \pm 0.23$ & $67.25 \pm 10.06$ & $0.08 \pm 0.02$ \\
$\mathrm{D}$ & $0.34 \pm 0.05$ & $0.19 \pm 0.04$ & $2.74 \pm 0.53$ & $79.98 \pm 16.03$ & $0.08 \pm 0.03$ & $79.08 \pm 14.69^{*}$ & $0.10 \pm 0.02$ \\
& & & & & & & \\
$\mathrm{E}$ & $0.29 \pm 0.06$ & $0.21 \pm 0.05$ & $2.83 \pm 0.85$ & $85.53 \pm 24.52$ & $0.08 \pm 0.06$ & $82.67 \pm 16.61$ & $0.12 \pm 0.04$ \\
& & & & & & & \\
\hline Total & $0.33 \pm 0.10$ & $0.21 \pm 0.05$ & $2.85 \pm 0.73$ & $87.90 \pm 19.77$ & $0.09 \pm 0.11$ & $71.85 \pm 17.01$ & $0.10 \pm 0.04$ \\
\hline
\end{tabular}

Keys: $A=$ Olfactory bulb, $B=$ Cerebral cortex. $C=$ Thalamus, $D=$ Hippocampus, $E=$ Cerebellum.

*Significantly higher in females than males

Fe was the most abundant metal in all the brain regions (89.54 ppm) while Mo had the least values (Tables 1 and 2, Figures 1 and 3). A significant sex difference was observed in the levels of $\mathrm{Zn}$ in the cerebral cortex and the hippocampus between the females and males (see Tables 2 and 3 ).

The mean concentration of Fe in the olfactory bulb was significantly different from that of the thalamus, hippocampus and the cerebellum, while that of the cerebral cortex was significantly different from the hippocampus. The mean concentration of $\mathrm{Zn}$ in the olfactory bulb was found to be significantly different for the cerebral cortex, thalamus, and the hippocampus: the concentration in the cerebral cortex was significantly different from the thalamus and hippocampus; the concentration in the cerebellum was also significantly different from those of the cerebral cortex, thalamus and hippocampus (Table $1)$.

\section{DISCUSSION}

Iron metal can pose a significant risk to brain development through its role as a potent oxidant stressor (Greesens et al, 2002). Also, iron has been shown to be important in the brain as impaired acquisition leads to neurological problems (Connor et al, 2003). The brain normally contains a substantially greater concentration of iron than other metals (Yehuda and Youdim, 1988), usually in the form of ferritin not heamosiderin (Octave et $a l, 1983)$. In the study, the concentration of iron was highest in the olfactory bulb; this contrasts 
with the finding of Riederer et al, 1989 who reported the highest iron concentration in the basal ganglia. Although, the highest concentration of Zinc was found in the cerebellum, it was also very high in the olfactory bulb, which correlates with the work of Persson (2003). The reason for the increased $\mathrm{Zn}$ level in the cerebral cortex and hippocampus of the female relative to the male can be further investigated.

The highest accumulation of copper was in the olfactory bulb. This is consistent with the findings of Ono and Cherian (1999) in rats. The mean concentration for the whole brain was slightly lower than the mean cortical dry weight concentration of $3.08 \mathrm{ppm}$ reported by Olopade $e t$ al (2005b) in goats.

Aluminum is a potent neurotoxicant in humans and animals (Yokel, 2000). The metal is environmentally ubiquitous and the usual human exposure route is primarily dietary (Yokel, 2000). Experimental evidence had supported the hypothesis that chronic exposure to low levels of Al may lead to neurological disorders (Joshi, 1990). This study revealed that the highest level of brain $\mathrm{Al}$ was in the olfactory bulb as observed by Sunderman Jnr (2001), followed by the cerebellum. Al was observed to accumulate in all regions of the brain with maximum accumulation in the hippocampus (Vasishta and Gill, 1990). In rats, the concentration was high in the hippocampus and thalamus (Nayak and Chatterjee, 2002). There were no significant differences between the sexes.

Although Mo was discovered to accumulate in all organs including the brain and pituitary (Haywood et al, 1998), this study showed that Mo is kept at a relatively low concentration in the different brain regions of goats with a mean concentration of $0.08 \mathrm{ppm}$ without any significant differences between the sexes. Mo in the form of Ammonium tetrathiomolybdate (TTM) is used to treat chronic $\mathrm{Cu}$ poisoning in sheep and has been recommended in Wilson's disease, although recent findings question the long term safety of the drug.

The fact that the level of vanadium is consistently higher in the olfactory bulb than the other regions is important in view of the role of Vanadium as a pollutant in the petroleum industry.
Va has been reported to cause major alterations of lipid profiles and protein concentration in all the brain regions and also leads to the comprehensive degradation of lipids in different brain regions with a concomitant elevation of ganglioside levels (Sasi et al, 1994). This is of great importance in developing countries especially since human habitations are sometimes located so close to the factories.

The value of $\mathrm{Pb}$ in this study is slightly higher than the value obtained in goats by Olopade et al, 2005b in our laboratory. This metal was seen to be more concentrated in the cerebellum followed by the olfactory bulb and lowest in the hippocampus. Brain exposed to lead has been reported to develop oxidative stress (Wang et al, 2006) while in sheep $\mathrm{Pb}$ poisoning is a differential diagnosis for polioencephalomalacia (Merck's manual, 2005).

Analysis of variance revealed that the most significant differences in metal concentrations across the brain regions occurred with $\mathrm{Fe}$ and $\mathrm{Zn}$.

The olfactory bulb had the highest concentrations for $\mathrm{Va}, \mathrm{Cu}, \mathrm{Fe}, \mathrm{Mo}, \mathrm{Al}$, while it had the second highest concentration for $\mathrm{Pb}$ and $\mathrm{Zn}$. This high level of all metals in the olfactory bulb may be indicative of prevailing environmental pollution in the population studied although the area where this study was done is devoid of heavy industry. It is suggested that low scale industrial activities and solid waste pollution prevalent in the study area could be contributing significantly to environmental pollution.

The results of the study could play a relevant role in predicting the level of exposure of humans to metals in the environment and can serve as basis for comparison with goats that have been raised in highly polluted environments.

\section{Acknowledgements}

The authors acknowledge the technical support of $\mathrm{Mr}$ Popoola of the Federal University of Technology, Akure, Ondo State, Nigeria.

\section{REFERENCES}

Bascom, R., 1996. Health effects of outdoor pollution. Am. J. Respir. Crit. Care Med., 153 (1): 3-50.

Benas, B., 1968. A new method for decomposition and 
comprehensive analysis of silicates by atomic absorption spectrometry. Analytical Chemistry, 40, 1682-1686.

Calderon-Garciduenas, L., Azzarelli, B., Acune, H., Garcia, R., Gambling, T.M., Osnaya, N., 2002. Air pollution and brain damage. Toxicol Pathol., 30 (3): 373-389.

Connor, J.R., Boyer, P.J., Menzies, S.K., Dellinger, B., Allen, R.P., Ondo, W.G., and Earley, C.J., 2003. Brain iron acquisition in restless leg syndrome. Neurology, 61: 304-309.

FAO, 1995. Food and Agricultural Organisation, Quarterly Bulletins of Statistics. FAO, 8.

Gall, C.F., 1996. Goat breeds of the world. $1^{\text {st }}$ edition. Margraf. Verlag. Weikershem. Germany. 1996.

Haywood, S., Dincer, Z., Holding, J., Parry, N.M., 1998. Metal (molybdenum, copper)

accummulation and retention in the brain, pituitary and other organs of ammonium treated sheep. Br J Nutr., 79(4): 329-31.

Joshi, J.G., 1990. Aluminum, a neurotoxin which affects diverse metabolic reactions. Biofactors., 2(3): 163-169.

Merck's Manual, 2005. Merck Veterinary Manual, Edition on Polioencephalomalacia in sheep. www.merckvetmanual.com/mvm/htm/bc/101900htm

Nayak, P., and Chatterjee, A.K., 2002. Response of regional brain glutamate transaminases of rat to aluminum in protein malnutrition. BMC Neurosci., 3,12 .

http://www.pubmedcentral.nih.gov/articlerender.fcgi?ar tid=126260\&tools=bot.

Octave, J.N., Schneider, Y.J., Crichton, R.R., Trouet, A., 1983. Iron mobilization from cultured hepatocytes: effect of desferrioxamine B. Biochem Pharmacol. 15, 32(22): 3413-3418.

Olopade, J.O., Onwuka, S.K., Adejumo, D., Ladokun, A.A., 2005a. Analysis of some industrial metals and ions in the cerebral cortex of goats in Nigeria. Nig. Vet. Journal 26(2): 51-55.

Olopade, J.O., Adejumo, D., Ladokun, A.O., Okandeji, M.E., Adeshina, A.A., Onwuka, S.K., 2005b. Preliminary studies on the cortical concentrations of metals and protein in the brain of two breeds of goats in Nigeria. Afr. J. Biomed. Res. 8: 191196.

Ono, S., Cherian, M.G., 1999. Regional distribution of metallothionein, zinc, and copper in the brain of different strains of rats. Biol Trace Elem Res., 69(2): 151-159.

Persson, E., Henriksson, J., and Tjalve, H., 2003. Uptake of cobalt from the nasal mucosa into the brain via olfactory pathways in rats. Toxicol. Lett., 145: 1927.

Riederer, P., Sofic, E., Rausch, W., Schmidt, B., Reynolds, G. P., Jellinger, K., Youdim, M.B.H., 1989. Transition Metals, Ferritin, Glutathione, and Ascorbic Acid in Parkinsonian Brains. Journal of Neurochemistry, 52(2): 515-520.

Sasi, M.M., Haider, S.S., el-Fakhri, M., Ghwarsha, K.M., 1994. Microchromatographic analysis of lipids, protein and occurrence of lipid peroxidation in various brain areas of vanadium exposed rats: a possible mechanism of vanadium neurotoxicity. Neurotoxicology, 15(2): 413-20.

Sunderman, F. W Jr ., 2001. Nasal toxicity, carcinogenicity and olfactory uptake of metals. Ann. Clin Lab Sci. 31(1): 3-24.

Vasishta, R.K., Gill, K.D., 1990. Distribution of Aluminum in different brain regions and body organs of rat. Biol. Trace Elem Res 52 (2): 181-92.

Wang, X., Oberlea, D., Yang, M.T., and Yang, S.P., 1992. Molybdenum requirement of female rats. J. Nutr. 122(4): 1036-41.

Wang, J., Wu, J., and Zhang, Z., 2006. Oxidative stress in mouse brain exposed to lead. Annals of Occupational Hygiene.

http://annhyg.oxfordjournals.org/cgi/content/abstract/m ei079v1.

Yehuda, S and Youdim, M.B.H., 1988. Brain iron deficiency: Biochemistry and behavior. In: M. B. H. Youdim (Ed.), Brain Iron. London: Taylor and Francis, 89-114.

Yokel, R.A., 2000. The toxicology of aluminum in the brain: a review. Neurotoxicology., 21(5): 813-828. 